(Orientalism, p. 328) that the former is likely to undergo as a result of contact with the latter - in other words, it is vital that we learn the lesson that Orientalism still has to teach.

DENNIS GRAFFLIN

Bates College

\title{
More on The Anthropology of Taiwanese Society
}

As a rapporteur for the conference that gave rise to The Antbropology of Taiwanese Society, edited by Emily Martin Ahern and Hill Gates, I must protest the narrow and cursory treatment the volume received in the book review section of the November 1982 JAS (42, no. 2:119-20). Although the reviewer did accurately pinpoint one of the book's main weaknesses (see below), the review itself had several weaknesses that need to be pointed out to readers of this journal who may be unfamiliar with the book and its background.

First, the review did not fulfill one of the central tasks of a book review, which is to tell the reader what is in the book. Rather, the reviewer highlighted a few pieces that touched on issues relevant to his theoretical preferences and, with one exception, ignored the rest. Second, he presented his preferred approach, "dialectical anthropology," as one that is "prominent in anthropological discussions." This may be true in France, but in most parts of the world neo-Marxist approaches are peripheral to the concerns of the vast majority of anthropologists. Thus, it seems like an inappropriate standard by which to judge the papers in this volume. Finally, the review fails to indicate how the book relates to previous work on Taiwan. As a result, the reader of the review is left unaware of the book's critical role in the self-definition and further development of the field of Taiwanese anthropology. In the few paragraphs available to me, I hope to fill in some of these gaps and to underscore the neglected strengths of the volume.

Briefly, this book and the conference from which it stemmed represent a highly ambitious attempt to summarize and synthesize the major subfields of Taiwan anthropology. Prior to this conference, Taiwan anthropology consisted of a few monographs and many articles scattered in numerous journals. The conference served to define and, in so doing, to create a field of Taiwan anthropology where it did not previously exist, except perhaps in the minds of some of its practitioners. The five overview papers - on local and regional systems (Lawrence Crissman), ethnicity and social class (Hill Gates), economics and ecology (Burton Pasternak), national, regional, and local politics (Edwin Winckler), and domestic organization (Arthur Wolf)-played a critical role in this process of self-definition. In summarizing the existing studies, they exposed areas of ignorance and, particularly in the fields of politics and ethnicity and social class, began to fill in areas of knowledge that had been largely ignored by anthropologists during the previous twenty years. Finally, in synthesizing the existing literature, the overview papers developed new hypotheses that will serve to guide the next generation of Taiwan scholars. To ignore this is to ignore the main contribution of the book to the advancement of scholarly understanding of Taiwan.

Unfortunately, this contribution was marred somewhat by the late publication of the volume, a weakness that the reviewer generously failed to mention. His silence on 
this issue is no doubt due to the lamentable fact that gaps of five years between conferences and conference volumes are so common in the academic world that they are not considered worthy of mention.

It remains true, as the reviewer noted, that the anthropology of Taiwan has so far failed to link up with either Sinological or general anthropology. But many of the ten substantive papers, although not explicitly integrative or comparative, do contribute hypotheses and/or analytic tools that the next generation of scholars can extend to other contexts. In addition to the contributions of the three papers mentioned in the November review (those of Emily Martin Ahern, Chung-min Chen, and Harry Lamley), there are important contributions made by the seven other substantive papers. Among the bypotheses advanced are Lydia Kung's hypothesis that the experience of factory work reinforces young women's beliefs in their low social status; Gary Seaman's suggestion that men use ritual means to perpetuate negative beliefs about women's sexuality; Lung-sheng Sung's proposition that the distinction between two types of family property ownership provides a key to understanding class differences in the timing of family division; and Edgar Wickberg's hypothesis that the Ch'ing era land tenure system absorbed major changes introduced by the Japanese without undergoing significant change. Among the analytic tools developed are Stevan Harrell's adaptive-ecological approach to understanding intercommunity differences in social and religious organization; Edwin Winckler's triad of political roles - managers, contenders, publics - that can be used to link state and society at middle levels of political systems; and Alexander Chien-chung Yin's notion of patterned changes in the nature of migration and adaptive mechanisms used by migrants in developing societies.

As one of the most rewarding and accessible sites for research on Chinese society, Taiwan continues to be the source of important insights into the nature of Chinese social, cultural, and political and economic organization and the ways it changes under one type of political economic system. Despite its shortcomings, over the years this book will continue to provide insights of value to students of all Chinese societies.

SUSAN GREENHALGH

Center for Chinese Studies

University of California, Berkeley

\section{Still More on The Antbropology of Taiwanese Society: A Reply to Susan Greenhalgh}

Susan Greenhalgh takes me to task for a "narrow and cursory" review of Emily Ahern and Hill Gates, eds. The Anthroplogy of Taiwanese Society in the November 1982 JAS (42, no. 2: 119-20). Although I can well understand Greenhalgh's concern, as a participant in the conference which produced the papers, that their significance as a benchmark in the development of Taiwan anthropological studies be addressed more forcefully, the dramatic synthesis that the papers may have represented in 1976 had paled considerably by the time they reached my hands for purposes of review in 1982. A participant in the conference could perhaps have more effectively communicated this significance in a review, but we would all be a lot worse off intellectually if we 